\title{
Traumatic Chronic Irreducible Atlantoaxial Rotatory Fixation in Adults: Review of the Literature, With Two New Examples
}

\author{
ABOLFAZL RAHIMIZADEH, MD, WALTER WILLIAMSON, MD, SHAHAYEGH RAHIMIZADEH, MD \\ Pars Advanced and Minimally Invasive Manners Medical Research Center, Pars Hospital Affiliated to Iran University of Medical Sciences, Tehran, Iran
}

\begin{abstract}
Atlantoaxial rotatory fixation (AARF) is a rare condition in adults and is almost always due to an accompanying trauma. The first example of traumatic AARF in adults was reported by Corner in 1907 and since then only 55 adult cases with this rare traumatic scenario have been published so far. Approximately $80 \%$ of adults with traumatic AARF are diagnosed soon after the traumatic events. However, in the remaining casualties, the condition might be missed with some delay from the diagnosis to treatment.

If this pathology is diagnosed early enough, the conservative attempts for a closed reduction are usually effective. After closed reduction, external immobilization is required to prevent recurrence of the dislocation. However, with delayed diagnosis, the condition may remain refractory to traction on manipulation and require an open reduction instead. In the literature, such irreducible chronic AARFs are rarely reported, being confined to only 14 adult examples, in whom surgical intervention for correction of the deformity will be required. In such cases, release of the atlantoaxial facet joints is the first surgical step. In the subsequent step, reduction of the dislocated facet joints can be done via one of the already described maneuvers. As the final step, C1-C2 fixation will be necessary for prevention of re-dislocation.

Herein, 2 adult patients with chronic rotatory atlantoaxial dislocation of traumatic origin are presented. In both cases, cranial traction and manipulations were ineffective and therefore an open reduction procedure was proposed and accomplished via the posterior midline corridor. The transverse rod technique was implemented subsequent to the atlantoaxial facet release. After correction of the deformity, a C1-C2 fixation was accomplished followed by arthrodesis. In addition to the outlined procedure, an historical review of the literature on this subject from the beginning of 20 th century is demonstrated.
\end{abstract}

Cervical Spine

Keywords: atlantoaxial fact joint, C1 lateral mass screw, C2 pars screw, atlantoaxial rotatory fixation, spinal trauma, torticollis, traction

\section{INTRODUCTION}

Atlantoaxial rotatory displacement of traumatic origin is an uncommon disorder. Disruption of the paired alar ligaments in traumatic events has been implicated as the most possible pathogenic factor in occurrence of this anomaly and characterized by the asymmetric displacement of the $\mathrm{C} 1$ articular mass on its corresponding counterpart, the lateral mass of C2. ${ }^{1,2}$

Corner $^{3}$ in 1907 used the term "dislocation" for such rotatory displacement. Wortzman and Dewar" introduced the term "subluxation" in 1968. ${ }^{4,5}$ However, Fielding and Hawkins ${ }^{1}$ in 1977 deliberately called it "rotatory fixation" and since then, the term "fixation" has become the hallmark term used to indicate the displacement that may arise from either subluxation or dislocation. Corner ${ }^{3}$ gave the first description of an adult with traumatic rotatory displacement of the atlantoaxial segment within medical literature in 1907. The case he presented was an officer who had fallen from a horse and sustained this particular traumatic injury. Later, in 1910, Mixter and Osgood ${ }^{5}$ reported 2 more adult cases in which high-energy traumas were responsible. These 2 patients were treated with only Thomas collars, and the therapeutic results were described as fair. ${ }^{5}$

The literature contains no more adult examples until Rankin's ${ }^{6}$ paper in 1936 that described 3 adult individuals with atlantoaxial rotatory fixation (AARF). Since that time, there have been 49 more adult cases that have been reported with the same condition so far. ${ }^{7-38}$ 
Management of AARF in adults and children is the same, and cranial traction has remained the first line of treatment in both groups. ${ }^{1,2,6-8,15,17,18,24-27,29-32 ; 37,39-44}$ This is particularly true when the condition is diagnosed early. ${ }^{1,2,6-8,15,17,18,24-27,29-32 ; 37,39-44}$ However, with a considerable delay in diagnosis, and from the diagnosis time to the initiation of treatment, the condition might remain refractory to conservative measures, particularly in adults. ${ }^{3-5,10,16,19-23,28,36}$ In such instances, release of the corresponding facet joints and their reduction with subsequent external or internal fixation will be justified. ${ }^{3-5,10,16,19-23,28,36,40-54}$ The surgical intervention for achievement of these issues can be done via anterior, extreme lateral and posterior approaches. ${ }^{10,19,21,28,36,38-61}$

Among these corridors, the posterior approach is more advantageous, since all steps of surgery could have been done in 1 stage with fewer approachrelated complications. Six different techniques for atlantoaxial joint release and reduction via conventional posterior approach have been described. ${ }^{55-61}$ To our belief, among the existing techniques, the transverse rod technique, which has been done already in a child with chronic AARF by Rajasekaran et $\mathrm{al}^{61}$ in 2010, seems more promising. Herein, 2 adult patients with chronic irreducible AARF of traumatic origin are presented. In both of these cases, unlocking of the atlantoaxial facet joints was done with transverse rod technique via conventional posterior approach. Besides, thorough review of all reported adults with AARF in English literature from 1900 to 2018 were done. However, our objectives are to not only emphasizing on the rarity of this traumatic event in adults and review of the literature, but also to focus on the validity of transverse rod technique in reduction of all types of chronic atlantoaxial dislocations.

\section{CASE REPORTS}

\section{Case 1}

A 56-year-old man was admitted to our hospital with painful head tilt of the neck. Three months earlier, he had been in a car accident. Subsequently, he was admitted to a local hospital with a chief complaint of severe neck pain and stiffness. Cervical radiographs were taken upon arrival and had appeared to be normal. He was diagnosed with cervical sprain and associated cervical muscle spasm and was discharged home after 1 day with a soft collar despite patient's persistent complaints, and the issue remained neglected. Three months after the injury, he was referred to our clinic with persistent neck pain and a head tilt. Clinical examinations revealed a locked head facing toward the left with fixation of the neck compatible with typical cockrobin fixed torticollis. A clinical diagnosis of AARF was then designated.

The initial plain cervical radiographs of the injury were reviewed, and a rotated atlas was discovered. This was best evidenced by the demonstration of the atlas rotation and the foramen transversarium on the lateral cervical view (Figure 1a). An open mouth $\mathrm{x}$-ray could not be done on account of the exquisite pain and difficulty in the positioning of the patient. Subsequently, a computed tomography (CT) scan with reformatted sagittal and coronal images of the C1-C2 complex was performed. This disclosed the forward displacement of the left lateral mass of $\mathrm{C} 1$ onto the corresponding articular mass of $\mathrm{C} 2$ with an apparent engagement present (Figure 1b). The right lateral mass of $\mathrm{C} 1$ appeared to be displaced posteriorly, where the dense was in asymmetrical position with respect the lateral masses of atlas. However, the distance between the arch of the atlas and the odontoid was within the normal range, indicating the integrity of the transverse ligament (Figure 1c). These features as well as the reconstructed 3D images were in a favor of "type I" AARF (Figure 1d). The cervical magnetic resonance imaging (MRI) was normal in particular at the upper levels. The possibility for a surgical intervention was described for the patient and his family and was accepted.

In the first hours following his admission, the patient was initially placed in a skull Gardner-Wells tong to try and demonstrate a correction without intervention. Traction was started with $3 \mathrm{~kg}$, and the weight was increased gradually to $12 \mathrm{~kg}$ within 3 days without much success despite the use of an oral muscle relaxant and narcotics. Therefore, surgical intervention was again decided, proposed, and accepted.

After induction of general anesthesia and while the skull traction was continued, the last attempts for reduction were attempted by digital pharyngeal manipulation. After the manipulations failure, the patient was flipped onto the prone position and a posterior midline incision was made. After stripping the muscles off the laminas, the right $\mathrm{C} 1$ and $\mathrm{C} 2$ lateral masses were exposed without difficulty. On the left side, the exposure of the affected facet joint 

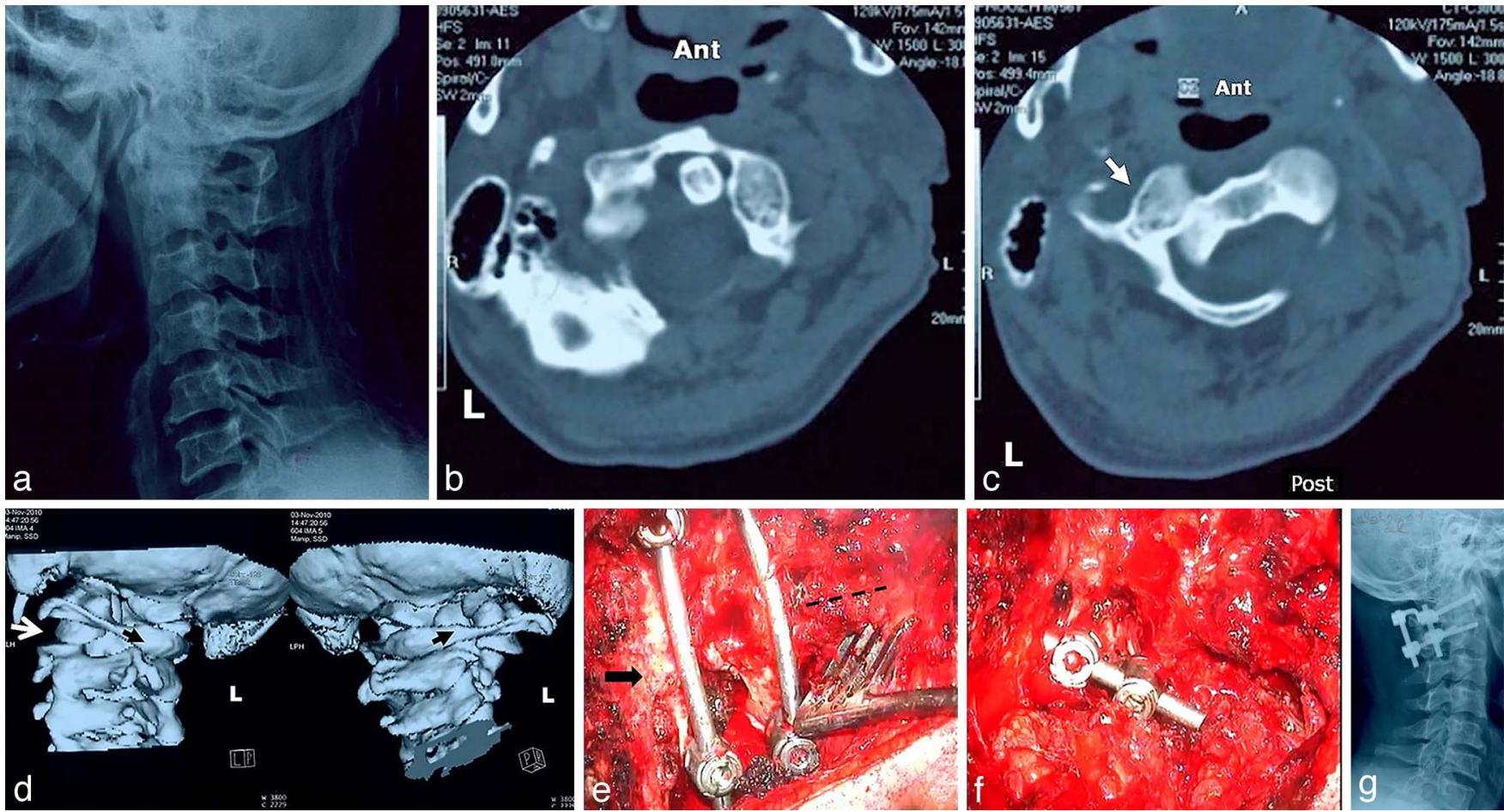

Figure 1. (a) Lateral cervical radiograph: shows rotation of atlas and demonstrating foramen transversarium indicating rotation of atlas. (b) Axial computed tomography (CT) scan: demonstrated deviation of odontoid toward right lateral mass of atlas. (c) Axial CT scan showing the lateral mass of C1 in front of C2 lateral mass (white arrow). (d) Reconstructed 3D CT image showing backward displacement of right C1 lateral mass (white arrow) and forward displacement of left C1 lateral mass; note deviation of the posterior arch of atlas to left (black arrow). (e) Intraoperative view: demonstrating transverse rod technique. Note deviated spinal process of C1 (black arrow) with respect to C2 spinal process. Forward displacement of C1 lateral mass is also observed. (f) Intraoperative view shows switching to C1-C2 screw rod fixation on the left side. $(\mathrm{g})$ Postoperative x-ray shows $\mathrm{C} 1-\mathrm{C} 2$ screw-rod hook fixation.

became possible only after excision of the $\mathrm{C} 2$ nerve root. At that time, a part of the left lateral mass of $\mathrm{C} 1$ appeared to be obscured by the $\mathrm{C} 2$ lateral mass. Nonetheless, after enough exposure of the posterior atlantoaxial facet joints, polyaxial screws were placed within the $\mathrm{C} 1$ lateral masses and in the $\mathrm{C} 2$ pedicles at both sides. Then the $\mathrm{C} 1-\mathrm{C} 1$ lateral masses screws were connected with a rod making a temporary transverse construct (Figure 1e). Later, the $\mathrm{C} 2$ pedicle screws were connected in the same manner with a transverse rod. Subsequently, for the reduction maneuver, a $\mathrm{C} 1-\mathrm{C} 1$ transverse complex was pulled cranially, backward, and to the right while the transverse $\mathrm{C} 2-\mathrm{C} 2$ construct was manipulated caudally. This was continued until the characteristic pop sound was heard, compatible with reduction. At this time, full alignment of the atlas and axis was demonstrated.

Later, the nuts of these complex constructs were loosened and opened with removal of the temporary rods, solid stabilization was subsequently achieved by making a C1-C2 screw rod construct or harms construct on the left side (Figure 1f). However, on the right side, $\mathrm{C} 1$ lateral mass screw was retrieved and replaced with a $\mathrm{Cl}$ laminar hook since the perforation of the anterior cortex of $\mathrm{C} 1$ lateral mass by the corresponding screw was highly suspected. This hook was connected to the corresponding right C2 screw, and the nuts were tightened forming a slight compression. The patient's postoperative course was uneventful and his torticollis disappeared. Postoperative radiographs showed atlantoaxial fixation with the screws and the hook in their proper place (Figure 1g). Now, several years after surgery, via a cell phone interview, we have found that he is doing very well.

\section{Case 2}

A 33-year-old woman was admitted with neck pain and tilt head of 2 months duration after sustaining severe trauma during a car accident. Immediately after the accident, she became quadriparetic due to a subaxial cervical spine injury for which corpectomy and fusion C6 vertebral body had been accomplished 2 days after the trauma. Despite a remarkable rebound following the surgery and near to complete recovery of neurological deficit within 2 months, the patient started to 
complain of persistent neck pain and subsequently her neck deformity was noticeable by her close family (Figure 2a). In cervical MRI taken at this time, the features of C6 corpectomy, a fibula allograft and plate, were discovered where the upper cervical levels seemed normal. Computerized tomography of the atlantoaxial territory in axial views demonstrated displacement of the dense toward the left $\mathrm{C} 1$ lateral mass and forward subluxation of the left $\mathrm{C} 1$ lateral mass overlapping the corresponding C2 lateral mass (Figure 2b). Reconstructed sagittal and coronal CT images showed an abnormal positioning of the odontoid with a rotation toward to the right lateral mass of the atlas, forward displacement of the lateral mass of atlas, and backward displacement of the right lateral mass of C1 (Figure 2c). With respect to these features, diagnosis of AARF was made.

Following neck traction for 2 weeks with no observed improvement on the present deformity, along with a failed manipulation under anesthesia at the same local hospital, she was transferred to our hospital as an irreducible pathology (Figure 2d). Upon admission, she was complaining of neck pain, deformity, and tempro-mandibular joint pain.

With the diagnosis of an irreducible "type I" AARF, the patient underwent surgery for an internal reduction. Under general anesthesia and with the patient in the prone position, the $\mathrm{C} 1$ and $\mathrm{C} 2$ posterior arches were exposed via a midline incision. After incising the $\mathrm{C} 2$ nerve root on left side, the corresponding atlas lateral mass and later right $\mathrm{C} 1$ lateral mass were exposed. The right lateral mass was subluxed posteriorly where the left lateral mass was subluxed anteriorly compatible with a "type I" AARF. Subsequently, the C2 pedicle screws were inserted on both sides, and the osteotom was placed inside the left $\mathrm{C} 1-\mathrm{C} 2$ interfacet joint. At this point with rotation of the osteotomy, the corresponding joint could be released. Afterward, the right and left $\mathrm{Cl}$ screws were attached with a transverse rod and fixed by tightening the nuts (Figure 2e). The same method was performed for both of the $\mathrm{C} 2$ screws. Thereafter, the $\mathrm{C} 1-\mathrm{C} 1$ transverse rod was held with a rod holder near to the left $\mathrm{C} 1$ screw and was pulled back cranially and to the right. At the same time, the $\mathrm{C} 2-\mathrm{C} 2$ rod was simultaneously pulled caudally until a click was heard and the deformity was corrected. After unlocking, the transverse rod was then removed, and a C1-C2 screw-rod fixation or Harm's technique was performed on both sides (Figure 2f).

The postoperative course was rather uneventful, and the patient's torticollis was corrected as well as her trismus (Figure 2g). Postoperative radiographs were compatible with a correction of the presenting deformity (Figure $2 \mathrm{~h}$ ). She was discharged 2 days after surgery. At 14 months' follow-up, she is doing very well and her cervical $\mathrm{x}$-ray shows good arthrodesis.

\section{DISCUSSION}

The atlantoaxial articulation is a complex joint that provides the pivot for craniocervical rotation. This joint is mainly stabilized by the transverse and alar ligaments. ${ }^{1-37,40-44,48,49,51,54,60}$ The transverse ligament prevents an excessive anterior shift of the atlas on the axis, whereas the paired alar ligaments prevent an excessive rotation. Alar ligament tears can lead to an asymmetrical displacement of the $\mathrm{C} 1$ lateral mass onto the $\mathrm{C} 2$ articular mass resulting in an AARF. Associated transverse ligament disruptions can result in even more serious rotatory dislocations. ${ }^{1-37,40-44,48,49,51,54,60}$

Clinically, a patient with AARF presents with abnormal head position and limited neck motion. The pathology exhibit characteristic cock-robin posture in which the head is rotated toward the opposite to the side of the anteriorly displaced $\mathrm{C} 1$ facet and the neck is tilted toward the affected facet. ${ }^{1-37,40-44,48,49,51,54,60}$

Traumatic AARF is most often observed in children and adolescents, and its occurrence in adults is regarded as a rare event. ${ }^{1-37,40-44,48,49,51,54,60}$ In children, traumas of a more minor intensity can result in AARF but in adulthood such traumatic deformities require a relatively high energy trauma. ${ }^{3-37}$ Such traumas may even cause lethality to the adjacent medulla or the vertebral arteries before presentation at a trauma center. ${ }^{3-37}$ Features such as a welldeveloped musculature, decreased elasticity, and the presence of relative ankylosis of the joints caused by degenerative changes become preventive factors in the development of this condition and contribute to its perceived rarity in adults. ${ }^{3-37}$

A careful search of the medical literature revealed that there are only 57 adults including these current cases with AARF that have existed since the beginning of the 20th century (Table). These include 32 males and 25 females. The higher reported instances in males are probably because of their 

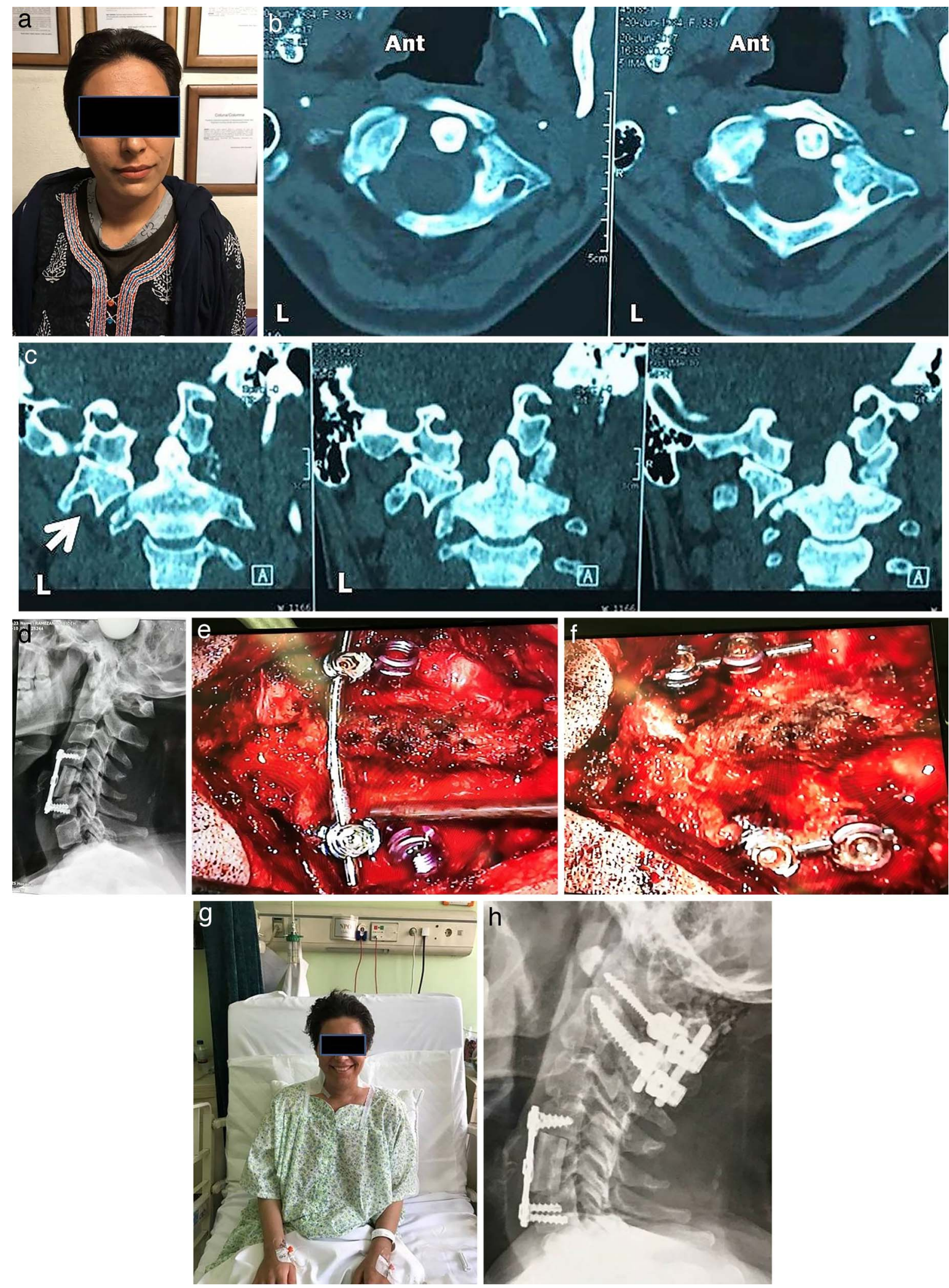

Figure 2. (a) The patient's photograph showing typical Cock-Robin posture. (b) Axial computed tomography (CT) scan demonstrating deviation of the odontoid to the right lateral mass of $\mathrm{C} 1$, as well as rotation of atlas. (c) Coronal reconstructed CT scan showing displacement of odontoid toward the lateral mass of C1 and forward displacement of $\mathrm{C} 1$ lateral mass. Right $\mathrm{C} 1$ lateral mass is gradually going backward and disappearing in these images. (d) Lateral cervical spine $\mathrm{x}$-ray with the patient under cranial traction; note the corpectomy of $\mathrm{C}$, replacement with expandable cage secured with plate. Rotation of the atlas and foramen transversarium is evident. (e) Intraoperative view, showing transverse screw rod construct. (f) Intraoperative view shows final C1-C2 screw rod Harms technique. (g) Postoperative patient's photographs demonstrating the patient a day after surgery being happy with correction of torticollis. (h) Postoperative lateral cervical radiograph demonstrating proper C1-C2 fixation. 
higher susceptibility to traumas. The age of the patients ranged from 19 to 58 with a mean of 32.8 years.

In 31 out of 56 cases, AARF was depicted and treated early on, $, 3,6,8-15,17,18,23-35,37$ where in 25 instances, the diagnosis was made with significant delay. ${ }^{4-6,11,16,18-22,24,36}$ Hopefully, our review shows that only 25 out of 31 cases of the early diagnosed adults responded to traction and manipulation, whereas only 6 cases remained refractory to conservative measures..$^{3,5,11,22,28}$ Four out of these 6 cases were left untreated, but in the first 4 decades of 20th century, and the remaining 2 underwent a surgical open reduction. Such reductions were shown to be successful in these 2 cases. $^{23,28}$

To properly categorize the delayed events, if the interval from the trauma to the treatment is after 1 month, but less than 6 months, the injury is designated as chronic. Those who are diagnosed and managed after 6 months are referred to as remote. Eventually, a chronic AARF that is the result of a delayed diagnosis and a subsequent delay in management is more refractory to conservative treatments. This means that the lesion in adults is not as easily correctable as it is in children and may require a long-term cranial traction. ${ }^{6,10,20,25}$ In these cases, the rate of success decreases in proportion to the length of the delay. This rate is also influenced by the patient's age. Aging causes the joints to become stiffer and the corresponding ligaments are less elastic, making the reduction more difficult overall. This does not mean that a reduction of chronic displacements is always impossible through conservative means. However, in longstanding AARFs with patience, application of sufficient weight, long-lasting traction and manipulation, the surgeons might overcome the irreducible fixation caused by fibrosis, scarring, and displacement. ${ }^{6,11,20,24}$ Current survey shows that 6 out of 25 chronic cases respond to traction or combination of manipulation and traction.

Nonetheless, if an adult with chronic AARF responds to traction or manipulation, the patient will require further immobilization in order to prevent a recurrence. This goal can be reached through either an external or an internal immobilization. However, the choice between an external immobilization and internal stabilization depends wholly on the compliance of the patient, the integrity of the transverse ligament, and the associated odontoid fracture. This means that for proper treatment an AARF needs to receive its proper categorization. One of the most important issues in selecting the most appropriate treatment can be based on the type of AARF classification described in 1978 by Fielding and Hawkins. ${ }^{1}$ These surgeons classified AARFs into 4 types of increasing seriousness depending on atlantodental interval (ADI) and measuring the shift of atlas. However, this classification was drawn up before popularity of CT scan and was based on plain radiographs and tomography. Nowadays, one can correlate this classification with the CT scan features of the atlantoaxial complex.

In type I, the ADI is normal. In type II, the anterior shift of atlas caused by the subluxation is from 3 to $5 \mathrm{~mm}$ where in half of the cases, transverse ligament might remain intact. In type III, ADI is more than $5 \mathrm{~mm}$ indicating transverse ligament disruption. Type IV rotatory subluxation is associated with posterior shift of the both lateral masses of atlas, without apparent widening of ADI. Many authors believe in existence of severe instability in this type, but disruption of transverse ligament has been questioned by some other authors. Levine ${ }^{38}$ and later Wise et $\mathrm{a}^{16}$ described and added type $\mathrm{V}$ AARF in which rotatory dislocation of atlas and odontoid fracture concomitantly occur.

In chronic cases, after achievement of a closed reduction in less severe traumas like in the case of a type I or type II AARF, in order to prevent a recurrence of subluxation, the external immobilization has been advocated. Most authors propose the use of a hard collar, ${ }^{4,7,12,30,32,34}$ Minerva cast, ${ }^{6}$ Minerva orthosis, ${ }^{14,20}$ or halo vest ${ }^{11,22,24}$ for the duration of 12 weeks. However, in more serious traumas (eg, a type II AARF with MRI-documented transverse ligament disruption, a type III or type IV AARF where stability is hampered after closed reduction), internal fixation by various modes would be solidly justified. ${ }^{4}$ The same formulation should be used in those associated with odontoid fractures (type V).

In the case of multiple recurrences and in noncompliant patients, after a closed reduction, the internal fixation should be strongly considered. For this purpose, a variety of posterior fixation techniques have been advocated, including the following: posterior wiring methods, atlantoaxial laminar clamps, Megrel's C2-C1 transarticular 
screwing, and C1 lateral mass, C2 pedicle polyaxial screw-rod fixation. ${ }^{15}$

\section{Irreducible Chronic AARF}

Another probable scenario is when an open reduction is required in the adult refractory to close reduction, as it was observed in 19 adult cases with delayed diagnosed. ${ }^{10,16,19,21,23,28,36}$ Persistence of the displacement in a traumatic AARF with a failure of reduction is almost certainly due to damage of the joint capsule or the synovial enfolding and an interposition and invagination of the soft tissues into the joint that is further aggravated by muscle spasms and ligamentous contractures.

Our historical review of the early 20th century shows that the management of cases with an irreducible atlantoaxial joint had been through their immobilization in an unreduced position. ${ }^{3,5}$ This was associated with an acceptable outcome in less serious types while in more serious instances where there still existed the possibility for a marked ADI or odontoid fracture, deterioration of the neurology, and even sudden death. Such possibilities limited the overall use of this mode of treatment in these more complicated types. Later, a reduction by means of a backward pulling of the $\mathrm{C} 1$ arch through the aid of a strong sublaminar wire or with the application of towel clips were introduced. However, because of the inherent risk for debilitating results such as the possibility of a cord injury or a C1 laminar fracture, this approach was gradually abandoned.

Thereafter, fusion in situ without trying to unlock the joints was proposed by Fielding and Hawkins. ${ }^{1}$ This became popular and was used as the treatment of choice for a few decades. The concept of in situ fusion was preferred to a reduction because of a relative decrease in morbidity. It was defended as an acceptable method for the prevention of further slippage. ${ }^{1}$ Proponents of in situ fusion believed that a secondary and compensatory rotation at the atlanto-occipital joint had an ability to correct the deformity and prevent a resultant facial asymmetry. It was later discovered that subluxation cannot be reduced by means of traction or manipulation in majority of longstanding cases. Therefore, treatment from a forceful reduction was changed to release of the corresponding involved facet joints. For this purpose, $\mathrm{C} 1-\mathrm{C} 2$ facet joints should be cleared from all interposing scar tissues under constant cranial traction. This would then be followed by their disengagement as a remedy for irreducible torticollis due to AARF. ${ }^{10,16,19,21,23,28,36,41-54}$

For this purpose and after achievement of open intrafacetal release, closed unlocking might be performed through increasing the weight of traction and manipulation.

For failed cases, a number of surgical approaches and challenging techniques for release and subsequent open reduction of the locked $\mathrm{C} 1-\mathrm{C} 2$ facet joints have been recommended. ${ }^{41-54}$ Then such approaches have evolved over time, and the issue is still open for a great deal of discussion and reasoning. High anterior cervical, transoral, retropharyngeal, and extreme lateral approach were the routes that have been addressed specifically for this purpose. $^{10,16,19,21,23,28,36,41-54}$ After disengagement was achieved, some surgeons prefer to put the patient in external immobilization by using a halo vest, in particular in children. Their rationale had been to preserve neck rotation after removal of halo vest. However, with progress in surgical skills, surgeons such as Goto et $\mathrm{al}^{53}$ in 1998 and Fuentes et $\mathrm{al}^{19}$ in 2001, Wang et $\mathrm{al}^{22}$ in 2005, and Qi et al ${ }^{36}$ in 2015 preferred posterior internal fixation after anterior unlocking procedures where some others like Weiskopf ${ }^{21}$ in 2005 persist on anterior osteosynthesis open reduction in the patients who possessed a remote AARF. These techniques seemed superior and were the treatment of choice for a several years until the newest posterior-only approaches were introduced and later popularized. In these techniques, all steps of surgery could be accomplished as a single stage procedure via the posterior midline route. ${ }^{28,54-61}$ In all of these techniques, posterior facet joints release and intraoperative open reduction maneuvers have been followed by posterior C1-C2 fixation. These gradually became the most popular technique with regard to the familiarity of the spine surgeons with this corridor. ${ }^{28,54-61}$

The posterior only techniques for unlocking of the released facet joints have changed over time. Goel et $\mathrm{al}^{28,54}$ proposed releasing of the corresponding facet joints through the insertion of a small osteotome within the joint and its rotation. $\mathrm{He}$ could correct the deformity resulting from chronic AARF in an adult with $\mathrm{C} 1-\mathrm{C} 2$ screw. In this technique, after the placement of the plate, the C2 screw should be tightened first followed soon after, by tightening of $\mathrm{Cl}$ screw. Through this 
Table. Information about the 57 reported cases including; sex age, type of accident, time of diagnosis, type of the management and outcome. Delayed cases are bold.

\begin{tabular}{|c|c|c|c|c|c|c|c|c|}
\hline No. & Author & Year & Sex & Age & Cause & Time & Treatment & Outcome \\
\hline 1 & Corner $^{3}$ & 1907 & M & 21 & Fall & Early & Immobilization not reduced, collar & Fair \\
\hline 2 & Mixter and Osgood ${ }^{5}$ & 1910 & $\mathrm{~F}$ & 58 & Fall & Delayed & Not reduced + Thomas collar & Fair \\
\hline 3 & Mixter and Osgood ${ }^{5}$ & 1910 & $\mathrm{M}$ & $?$ & Fall & Delayed & Not reduced Thomas Collar & Fair \\
\hline 4 & Rankin $^{6}$ & 1936 & $\mathrm{~F}$ & 56 & Sport & Delayed & Traction + cast & Good \\
\hline 5 & Rankin $^{6}$ & 1936 & $\mathrm{~F}$ & 23 & Forceful move & Early & Traction + cast & Good \\
\hline 6 & Rankin $^{6}$ & 1936 & M & 51 & MVA & Delayed & Traction + cast & Good \\
\hline 7 & Wortzman and Dewar ${ }^{4}$ & 1968 & M & 32 & MVA & Early & Hard collar & Fair \\
\hline 8 & Wortzman and Dewar ${ }^{4}$ & 1968 & $\mathrm{M}$ & 28 & Mining accident & Delayed & Manipulation + Gallie fusion & Good \\
\hline 9 & Lulo and Goldstone ${ }^{7}$ & 1976 & M & 20 & MVA & Early & Traction + hard collar & Good \\
\hline 10 & Rinaldi et $\mathrm{al}^{8}$ & 1979 & M & 48 & MVA & Early & Traction failed & Poor \\
\hline 11 & Jones $^{9}$ & 1984 & M & 18 & Sport & Early & Did not tolerate traction \& collar & Fair \\
\hline 12 & Schmidek et $\mathrm{al}^{10}$ & 1986 & M & 24 & Diving & Early & Transmandibular reduction $+\mathrm{C} 0-\mathrm{C} 2$ fusion & Good \\
\hline 13 & Kowalski et $\mathrm{al}^{11}$ & 1987 & $\mathrm{~F}$ & 31 & Not defined & Early & Not reduced but cast & Fair \\
\hline 14 & Kowalski et $\mathrm{al}^{11}$ & 1987 & $\mathrm{~F}$ & 22 & Not defined & Early & Traction but no reduction + collar & Fair \\
\hline 15 & Kowalski et $\mathrm{al}^{11}$ & 1987 & M & 34 & Not defined & Delayed & Halo traction & Fair \\
\hline 16 & Von Holsbeeck and Mackay ${ }^{12}$ & 1989 & M & 48 & Assault & Early & Caliper traction + hard collar & Good \\
\hline 17 & Von Holsbeeck and Mackay ${ }^{12}$ & 1989 & M & 18 & Sport & Early & Halter traction + hard collar & Good \\
\hline 18 & Von Holsbeeck and Mackay ${ }^{12}$ & 1989 & $\mathrm{~F}$ & 22 & Forceful move & Early & Halter traction + hard collar & Good \\
\hline 19 & Robertson and Swan ${ }^{13}$ & 1992 & M & 18 & Sport & Early & Traction + Somi orthosis & Good \\
\hline 20 & Born et $\mathrm{al}^{14}$ & 1994 & $\mathrm{M}$ & 29 & Strike object & Early & Traction + Minerva orthosis & Good \\
\hline 21 & Moore and Frank ${ }^{15}$ & 1995 & M & 65 & MVA & Early & Traction + PWT + fusion & Good \\
\hline 22 & Vinchon et $\mathrm{al}^{16}$ & 1995 & $\mathrm{M}$ & 34 & Not defined & Delayed & Open reduction + laminar clamps & Good \\
\hline 23 & Wise et $\mathrm{al}^{17}$ & 1997 & $\mathrm{~F}$ & 29 & MVA & Early & Gardner traction + Halo vest & Good \\
\hline 24 & Liebner et $\mathrm{al}^{18}$ & 1998 & $\mathrm{~F}$ & 29 & MVA & Early & Traction + Halo vest & Good \\
\hline 25 & Fuentes et al ${ }^{19}$ & 2001 & M & 24 & Sport & Delayed & Open reduction + posterior laminar hooks & Good \\
\hline 26 & Castel et $\mathrm{al}^{20}$ & 2001 & M & 41 & Sport & Delayed & Traction, Minerva orthosis & Good \\
\hline 27 & Weisskopf et $\mathrm{al}^{21}$ & 2005 & M & 38 & Not defined & Delayed & Transoral reduction + osteosynthesis & Good \\
\hline 28 & Weisskopf et $\mathrm{al}^{21}$ & 2005 & M & 36 & Not defined & Delayed & Posterior reduction $+\mathrm{C} 0-\mathrm{C} 3$ fusion & Good \\
\hline 29 & Weisskopf et $\mathrm{al}^{21}$ & 2005 & $\mathrm{~F}$ & 21 & Not defined & Delayed & Transoral reduction + osteosynthesis & Good \\
\hline 30 & Weisskopf et $\mathrm{al}^{21}$ & 2005 & M & 26 & Not defined & Delayed & Posterior reduction + temporary fixation & Good \\
\hline 31 & Weisskopf et $\mathrm{al}^{21}$ & 2005 & $\mathrm{~F}$ & 23 & Not defined & Delayed & Transoral reduction + osteosynthesis & Good \\
\hline 32 & Wang et $\mathrm{al}^{22}$ & 2008 & $\mathrm{~F}$ & 44 & Not defined & Delayed & Immobilization with halo vest & Poor \\
\hline 33 & Kim et $\mathrm{al}^{23}$ & 2007 & M & 34 & Fall & Early & Open reduction, $\mathrm{PTW}+\mathrm{Harms}$ & Good \\
\hline 34 & Sinigaglia et $\mathrm{al}^{24}$ & 2008 & $\mathrm{~F}$ & 26 & MVA & Delayed & Closed reduction + halo vest & Fair \\
\hline 35 & Sinigaglia et $\mathrm{al}^{24}$ & 2008 & $\mathrm{~F}$ & 21 & MVA & Early & Closed reduction + halo vest & Good \\
\hline 36 & Sinigaglia et $\mathrm{al}^{24}$ & 2008 & M & 29 & MVA & Early & Closed reduction + halo vest & Good \\
\hline 37 & Jeon et $\mathrm{al}^{25}$ & 2009 & $\mathrm{~F}$ & 25 & MVA & Early & Hard collar & Good \\
\hline 38 & Singh et $\mathrm{al}^{26}$ & 2009 & $\mathrm{~F}$ & 25 & MVA & Early & Traction + halo vest & Good \\
\hline 39 & $\mathrm{Oh}$ et $\mathrm{al}^{27}$ & 2010 & M & 37 & Neck hit with brick & early & Traction + halo vest & Good \\
\hline 40 & Goel et $\mathrm{al}^{28}$ & 2010 & M & 28 & Fall & Early & Open reduction + halo vest & Good \\
\hline 41 & Marti et $\mathrm{al}^{29}$ & 2011 & $\mathrm{~F}$ & 24 & Forceful move & Early & Closed reduction + halo vest & Good \\
\hline 42 & Stenson ${ }^{30}$ & 2011 & $\mathrm{~F}$ & 31 & Fall & Early & Hard collar & Good \\
\hline 43 & Meza Escobar et al ${ }^{31}$ & 2012 & $\mathrm{~F}$ & 19 & MVA & Early & Traction + manipulation + soft collar & Good \\
\hline 44 & Venkatesan et $\mathrm{al}^{32}$ & 2012 & $\mathrm{~F}$ & 20 & MVA & Early & Traction + Hard collar & Fair \\
\hline 45 & Venkatesan et $\mathrm{al}^{32}$ & 2012 & $\mathrm{~F}$ & 52 & MVA & Early & Traction + halo vest & Fair \\
\hline 46 & Maida et $\mathrm{al}^{33}$ & 2012 & M & 27 & MVA & Early & Manipulation, Philadelphia collar & Good \\
\hline 47 & Han et $\mathrm{al}^{34}$ & 2014 & M & 22 & MVA & Early & Manipulation + Hard collar & Good \\
\hline 48 & Bellil et $\mathrm{al}^{35}$ & 2014 & $\mathrm{~F}$ & 56 & MVA & early & Manipulation + halo vest & Good \\
\hline 49 & Qi et $\mathrm{al}^{36}$ & 2015 & $\mathrm{~F}$ & 29 & Not specified & Delayed & Ant retropharyngeal $+\mathrm{C} 2-\mathrm{C} 1$ transarticular & Good \\
\hline 50 & Qi et $\mathrm{al}^{36}$ & 2015 & M & 34 & Not specified & Delayed & Ant retropharyngeal $+\mathrm{C} 2-\mathrm{C} 1$ transarticular & Good \\
\hline 51 & Qi et $\mathrm{al}^{36}$ & 2015 & $\mathrm{~F}$ & 57 & Not specified & Delayed & Ant retropharyngeal $+\mathrm{C} 2-\mathrm{C} 1$ transarticular & Good \\
\hline 52 & Qi et $\mathrm{al}^{36}$ & 2015 & M & 51 & Not specified & Delayed & Ant retropharyngeal $+\mathrm{C} 2-\mathrm{C} 1$ transarticular & Good \\
\hline 53 & Qi et $\mathrm{al}^{36}$ & 2015 & M & 33 & Not specified & Delayed & Ant retropharyngeal $+\mathrm{C} 2-\mathrm{C} 1$ transarticular & Good \\
\hline 54 & Qi et $\mathrm{al}^{36}$ & 2015 & M & 19 & Not specified & Delayed & Ant retropharyngeal $+\mathrm{C} 2-\mathrm{C} 1$ transarticular & Good \\
\hline 55 & Garcia Pallero et al ${ }^{37}$ & 2019 & $\mathrm{~F}$ & 28 & MVA & Early & Traction + manipulation + rigid collar & Good \\
\hline 56 & Current case 1 & 2018 & M & 56 & MVA & Delayed & Open reduction $+\mathrm{C} 1-\mathrm{C} 2$ Screw-rod hook & Good \\
\hline 57 & Current case 2 & 2016 & $\mathrm{~F}$ & 39 & MVA & Delayed & Open reduction + screw rod fixation & Good \\
\hline
\end{tabular}

Abbreviation: MVA, motor vehicle accident; PWT, posterior wiring technique.

technique, the displaced C1 lateral mass will then be pulled back, in the same manner that has been described for lumbar spondylolisthesis. ${ }^{28,54}$ In more fixed cases, after placement of C1 C2 poly axial screws and release of the $\mathrm{C} 1-\mathrm{C} 2$ facet joints, the corresponding dislocated $\mathrm{C} 1$ joint can then be pulled back with the application of a strong persuader. $^{55,56}$ Other than these, a few other reduction techniques in addition to releasing have developed. For example, in 2013, Suh et al ${ }^{57}$ introduced a technique where a temporary $\mathrm{T}$ shaped tool was used instead of an ordinary rod 
acting as a lever to pull back the $\mathrm{C} 1$ lateral mass screw.

In 2011, Liu et $\mathrm{al}^{58}$ described an advanced technique named posterior cable-dragged reduction/cantilever beam internal fixation surgery, where the atlas arm is pulled back with the aid of a cable tightened on the U-shaped rod that is already attached to bilateral C2-C3 screws. Another interesting method is the application of the posterior rotating rod strategy introduced by Chang-Wei et al. ${ }^{59}$ In this method, C1 lateral mass screws and C2 and $\mathrm{C} 3$ pedicle screws are inserted at appropriate points; subsequently, a curved rod with its convex side placed posteriorly is introduced in the tulips of the screws, and the nuts are tightened, but not fully. Then, 2 rod rotators are used such that both rods are rotated simultaneously until the rods are placed in a lordotic position resulting in reduction. ${ }^{59}$

Transverse-rod unlocking technique has been used in the current cases and has been introduced by Rajasekaran et $\mathrm{al}^{60}$ in a 13 -year-old child with chronic AARF. Accordingly, the proximal transatlantal construct is pulled cranially and backward in a very gentle action while the distal construct is pushed caudally until the characteristic pop is heard indicating the disengagement and restoration of alignment (Figure 3). Removal of the temporary rods and its switching to $\mathrm{C} 1-\mathrm{C} 2$ Harms construct can provide an immediate rigid internal fixation. ${ }^{60,61}$ This should also be coupled with arthrodesis with the application of a demineralized allograft mixed with bone marrow aspirate. We used this less challenging alternative technique for both of our cases, which are the first adults with AARF that have been reduced and fixed with this technique. We believe the current technique to be easy and more effective when compared with the previously described ones.

In all of the current techniques, the outcome after the reduction and internal immobilization seems to be very promising despite the fact that there is an inherent disadvantage with decrease in the rotation of the neck-a problem that neither can be prevented with unilateral C1-C2 fixations nor can be restored with early removal of the construct.

In summary, AARF is a rare event in adults and has traumatic origins in the majority of the cases. If the condition is diagnosed early enough, it can be managed with traction or manipulation. With correction of the deformity, external immobilization or internal fixation is then fully justified. In chronic
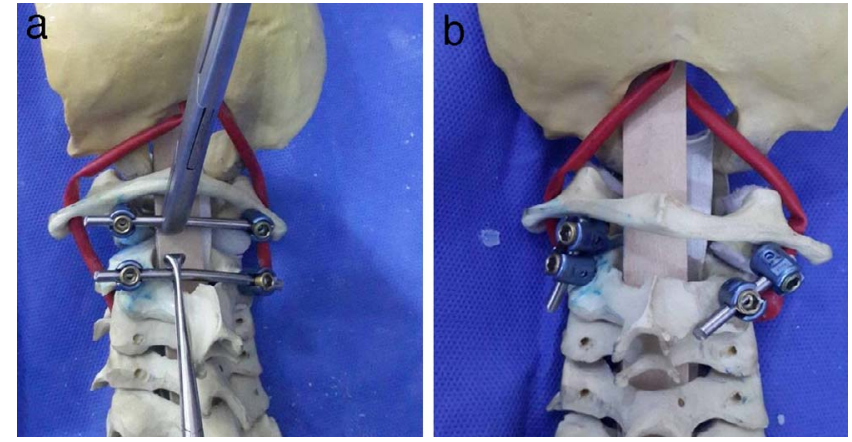

Figure 3. Transverse rod technique in plastic model, (a) C1-C1 rod construct is pulled cranially and $\mathrm{C} 2-\mathrm{C} 2$ construct caudally, (b) $\mathrm{C} 1-\mathrm{C} 2$ fixation after reduction with Harms technique.

cases, traction and manipulation should also be considered as the first line of treatment, but with its failure, the surgical release of the fact joints should be performed. This can be achieved through either the posterior route or by using the anterior corridor. Once the facet joints are released, open unlocking maneuver and internal fixation, with $\mathrm{C} 1-\mathrm{C} 2$ fixation should be done subsequently. Obviously, for the proper application of any of these corridors and techniques, a thorough knowledge of the unique anatomy of the atlantoaxial articulation is required.

\section{ACKNOWLEDGMENTS}

The authors appreciate Mrs Mona Karimi and Alireza Mojtahed for their efforts for providing this careful review. The authors have no interest to declare. Written informed consent was obtained from both patients.

\section{REFERENCES}

1. Fielding JW, Hawkins RJ. Atlanto-axial rotatory fixation (Fixed rotatory subluxation of the atlanto-axial joint). $J$ Bone Joint Surg Am. 1977;59(1):37-44.

2. Hicazi A, Acaroglu E, Alanay A, Yazici M, Surat A. Atlantoaxial rotatory fixation-subluxation revisited. Spine (Phil Pa 1976). 2002;27(24):2771-2775.

3. Corner EM. Rotary dislocations of the atlas. Arch Surg. 1907;45(1):9-26.

4. Wortzman G, Dewar FP. Rotary fixation of the atlantoaxial joint: rotational atlantoaxial subluxation. Radiology. 1968;90(3):479-487.

5. Mixter SJ, Osgood RB. Traumatic lesions of the atlas and axis. Ann Surg. 1910;51(12):193-207.

6. Rankin JO. Rotatory dislocation of atlas on axis. Am J Surg. 1936;32(1):27-36.

7. Lulo AD, Goldstone RA. Rotatory subluxation of the atlas on the axis. Ann Emerg Med. 1976;5(7):523-524.

8. Rinaldi I, Mullins WJ, Delaney WF, Fitzer PM, Tornberg 
DN. Computerized tomographic demonstration of rotational atlantoaxial fixation. J Neurosurg. 1979;50(1):115-119.

9. Jones RN. Rotatory dislocation of both atlanto-axial joints. J Bone Joint Surg Br. 1984;66(1):6-7.

10. Schmidek HH, Smith DA, Sofferman RA, et al. Transoral unilateral facetectomy in the management of unilateral anterior rotatory atlantoaxial fracture dislocation: a case report. Neurosurgery. 1986;18(5):645-652.

11. Kowalski HM, Cohen WA, Cooper P, Wisoff JH. Pitfalls in the CT diagnosis of atlantoaxial rotary subluxation. Am J Radiol 1987;149(3):595-200.

12. Von Holsbeeck EMA, Mackay NNS. Diagnosis of acute atlantoaxial rotatory dislocation. J Bone Joint Surg Br. 1989; 71B(1):90-91.

13. Robertson PA, Swan HAP. Traumatic bilateral rotatory facet dislocation of atlas on the axis. Spine (Phila Pa 1976). 1992;17(10):1252-1254.

14. Born CT, Mure AJ, Iannacone WM, DeLong WG. Three-dimensional computerized tomographic demonstration of bilateral atlantoaxial rotatory dislocation in an adult: report of a case and review of the literature. J Orthop Trauma. 1994;8(1):67-72.

15. Moore KR, Frank EH. Traumatic atlantoaxial rotatory subluxation and dislocation. Spine (Phila Pa 1976). 1995;20(17):1928-1930.

16. Vinchon $\mathrm{M}$, Assaker $\mathrm{M}$, Leclec X, Lejeune JP. Vertebrobasilar insufficiency resulting from traumatic atlantoaxial instability. Spine (Phila Pa 1976). 1995;36(4):839-841.

17. Wise JW, Cheney R, Fischgrund J. Traumatic bilateral rotatory dislocation of the atlantoaxial joints: a case report and review of the literature. J Spinal Discord. 1997;10(5):451-453.

18. Liebner E, Kaplan L, Sagiv S, Floman Y. Delayed closed reduction of rotatory atlantoaxial dislocation. Case report and literature review. J Trauma. 1998;44(4):731-734.

19. Fuentes S, Bouillot P, Palombi O, Desgeorgeores M. Traumatic atlantoaxial rotatory dislocation with odontoid fracture: case report and review. Spine (Phila Pa 1976). 2001;26(7):830-834.

20. Castel E, Benazet JP, Samaha C, Charolt O, Morin G, Saillant T. Delayed closed reduction of rotatory atlantoaxial dislocation in an adult. Eur Spine J. 2001;10(5):449-453.

21. Weisskopf M, Naeve D, Ruf M, et al. Therapeutic options and results following fixed atlantoaxial rotatory dislocations. Eur Spine J. 2005;14(1):61-68.

22. Wang C, Yan M, Zhou HT, Wang SL, Dang GT. Open reduction of irreducible atlantoaxial dislocation by transoral anterior atlantoaxial release and posterior internal fixation. Spine (Phila Pa 1976). 2006;31(11):E306-E313.

23. Kim YS, Lee JK, Moon SJ, Kim SH. Post-traumatic atlantoaxial rotatory fixation in an adult: a case report. Spine (Phila Pa 1976). 2007;32(23):E682-E687.

24. Sinigaglia R, Bundy A, Monterumici DA. Traumatic atlantoaxial rotatory dislocation in adults. Chir Narzadow Ruchu Ortop Pol. 2008;73(2):149-154.

25. Jeon SW, Jeong JH, Moon SM, Choi SK. Atlantoaxial rotatory fixation in adults patient. $J$ Korean Neurosurg Soc. 2009;45(4):246-248.

26. Singh VK, Singh PK, Balakrishnan SK, Leitao J. Traumatic bilateral atlantoaxial rotatory subluxation mimicking as torticollis in an adult female. J Clin Neurosci. 2009; 16(5):721-722.
27. Oh JY, Chough CK, Cho CB, Park HK. Traumatic atlantoaxial fixation accompanying odontoid and c2 articular facet fracture. J Korean Neurosurg Soc. 2010;48(5):452-454.

28. Goel A, Figueiredo A, Maheshwari S, Shah A. Atlantoaxial manual realignment in a patient with traumatic atlantoaxial joint disruption. J Clin Neurosci. 2010;17(5):672673.

29. Marti JJ, Zalacain JF, Houry DE, Isakov AP. A 24-yearold woman with neck pain. Am J Emerg Med. 2011;29(4):473.e1-473.e2.

30. Stenson D. Diagnosis of acute atlantoaxial rotatory fixation in adults. Radiography. 2011;17(2):165-170.

31. Meza Escobar LE, Osterhoff G, Ossendorf C, Wanner GA, Simmen HP, Werner CM. Traumatic atlantoaxial rotatory subluxation in an adolescent: a case report. J Med Case Rep. 2012;6:27.

32. Venkatesan M, Bhatt R, Newey ML. Traumatic atlantoaxial rotatory subluxation (TAARS) in adults: a report of two cases and literature review. Injury. 2012;43(7):1212-1215.

33. Maida G, Marcati E, Sarubbo S. Posttraumatic atlantoaxial rotatory dislocation in a healthy adult patient: a case report and review of the literature. Case Rep Orthop. 2012:183581.

34. Han ZM, Nagao N, Sakakibara T, et al. Adult traumatic atlantoaxial rotatory fixation: a case report. Case Rep Orthop. 2014;2014:593621.

35. Bellil M, Hadhari K, Sridi M, Kooli M. Traumatic atlantoaxial fixation associated with $\mathrm{C} 2$ articular facet fracture in adult patient: case report. J Craniovert Jun Spine. 2014;5(4):163-166.

36. Qi C, Xi Y, Chunguang Z, Limin L, Yueming S. Anterior retropharyngeal reduction and sequential posterior fusion for atlantoaxial rotatory fixation with locked C1-C2 lateral facet. Spine (Phila Pa 1976). 2015;40(21):E1121-E1127.

37. Garcia Pallero MA, Torres CV, Delgado-Fernandez J. Traumatic atlantoaxial rotatory fixation (AARF) in an adult. Eur Spine J. 2019;28(2):284-289.

38. Levine AM, Edwards CC. Traumatic lesions of the occipitoatlantoaxial complex. Clin Orthop. 1989;(239):53-68.

39. Phillips WA, Hensinger RN. The management of rotatory atlantoaxial subluxation in children. J Bone Joint Surg Am. 1989;71(5):664-668.

40. Subach BR, McLaughlin MR, Albright AL, Pollack IF. Current management of pediatric atlantoaxial rotatory subluxation. Spine (Phila Pa 1976). 1998;23(20):2174-2179.

41. Burkus JK, Desponte RJ. Chronic atlantoaxial rotatory fixation correction by cervical traction, manipulation, and bracing. J Pediatr Orthop. 1986;6(5):631-635.

42. Park SW, Cho KH, Shin YS, et al. Successful reduction for a pediatric chronic atlantoaxial rotatory fixation (Grisel syndrome) with long-term halter traction: case report. Spine (Phila Pa 1976). 2005;30(15):E444-E449.

43. Missori P, Miscusi M, Paolini S, et al. A C1-C2 locked facet in a child with atlantoaxial rotatory fixation. $J$ Neurosurg. 2005;103(6 suppl):563-566.

44. Ishii K, Toyama Y, Nakamura M, et al. Management of chronic atlantoaxial rotatory fixation. Spine (Phila Pa 1976). 2012;37(5):E278-E285.

45. Hao D, He B, Zheng Y, Zhang Z. Single stage anterior release and sequential posterior fusion for irreducible atlantoaxial dislocation. Clin Spine Surg. 2016;29(5):E240-E245. 
46. Park SH, Sung JK, Lee SH, et al. High anterior cervical approach to the upper cervical spine. Surg Neurol. 2007;68(5):519-524.

47. Liu T, Li F, Xiong W, et al. Video-assisted anterior transcervical approach for the reduction of irreducible atlantoaxial dislocation. Spine (Phila Pa 1976). 2010;35(15):14951501 .

48. Crockard HA, Rogers MA. Open reduction of traumatic atlantoaxial rotatory dislocation with use of the extreme lateral approach. A report of two cases. J Bone Joint Surg Am. 1996;78(3):431-436.

49. Crossman JE, David K, Hayward R, Crockard HA. Open reduction of pediatric atlantoaxial rotatory fixation: longterm outcome study with functional measurements. J Neurosurg Spine. 2004;100(3):235-240.

50. Lee ST, Fairholm DJ. Transoral anterior decompression for treatment of unreducible atlantoaxial dislocations. Surg Neurol. 1985;23(3):244-248.

51. Govender S, Kumar KP. Staged reduction and stabilization in chronic atlantoaxial rotatory fixation. $J$ Bone Joint Surg Br. 2002;84:727-731.

52. Lu G, Passias PG, Li G, et al. Endoscopically assisted anterior release and reduction through anterolateral retropharyngeal approach for fixed atlantoaxial dislocation. Spine (Phila Pa 1976). 2010;35(5):544-551.

53. Goto S, Mochizuki M, Kita T, Murakami M, Nishigaki $\mathrm{H}$, Moriya H. Transoral joint release of the dislocated atlantoaxial joints combined with posterior reduction and fusion for a late infantile atlantoaxial rotatory fixation. A case report. Spine (Phila Pa 1976). 1998;23(13):1485-1489.

54. Goel A, Kulkarni AG, Sharma P. Reduction of fixed atlantoaxial dislocation in 24 cases: technical note. $J$ Neurosurg Spine. 2005;2(4):505-509.

55. Harms J, Melcher RP. Posterior C1-C2 fusion with polyaxial screw and rod fixation. Spine (Phila Pa 1976). 2001;26(22):2467-2471.

56. Yin Y-H, Qiao G-Y, Yu X-G, Tong H-Y, Zhang Y-Z. Posterior realignment of irreducible atlantoaxial dislocation with C1-C2 screw and rod system: a technique of direct reduction and fixation. Spine J. 2013;13(12):1864-1871.
57. Suh B-G, Padua MRA, Riew KD, et al. A new technique for reduction of atlantoaxial subluxation using a simple tool during posterior segmental screw fixation: clinical article. $J$ Neurosurg Spine. 2013;19(2):160-166.

58. Liu X, Liu H, Li T, et al. Treatment of irreducible old atlantoaxial subluxation with cable-dragged reduction and cantilever beam internal fixation. Spine (Phila Pa 1976). 2011;36(15):E983-E992.

59. Chang-Wei L, Wei L, Zhen-Sheng M, Yan-Wu L, Long B, Nan Z. Posterior rotating rod reduction strategy for irreducible atlantoaxial subluxations with congenital odontoid aplasia. Spine (Phila Pa 1976). 2010;35(23):2064-2070.

60. Rajasekaran S, Avadhani A, Parthasarathy S, Shetty AP. Novel technique for reduction of a chronic atlantoaxial rotatory fixation using a temporary transverse transatlantal rod. Spine J. 2010;10(10):900-904.

61. Rahimizadeh A, Soufiani H, Rahimizadeh A. Management of irreducible atlantoaxial dislocation with horizontal screw-rod construct and technical note. World Spinal Col J. 2015;6(2):55-64.

Corresponding Author: Abolfazl Rahimizadeh, MD, Pars Advanced and Minimally Invasive Manners Medical Research Center, Pars Hospital Affiliated to Iran University of Medical Sciences, 63 Keshawarz Blvd, Tehran, Iran. Phone: +98 889600519; Cell phone: +98 9123226149; E-mail: a_rahimizadeh@hotmail.com.

Published 31 August 2019

This manuscript is generously published free of charge by ISASS, the International Society for the Advancement of Spine Surgery. Copyright (C) 2019 ISASS. To see more or order reprints or permissions, see http://ijssurgery.com. 